\title{
Collective Identity Supporting Sustainability Transformations in Ecovillage Communities
}

\author{
Ciska Ulug *(D), Lummina Horlings (D) and Elen-Maarja Trell \\ Department of Planning and Environment, University of Groningen, Postbus 800, \\ 9700 AV Groningen, The Netherlands; 1.g.horlings@rug.nl (L.H.); e.m.trell@rug.nl (E.-M.T.) \\ * Correspondence: c.r.ulug@rug.nl
}

Citation: Ulug, C.; Horlings, L.; Trell, E.-M. Collective Identity Supporting Sustainability Transformations in Ecovillage Communities.

Sustainability 2021, 13, 8148. https:// doi.org/10.3390/su13158148

Academic Editor: Allen R. McConnell

Received: 4 June 2021

Accepted: 18 July 2021

Published: 21 July 2021

Publisher's Note: MDPI stays neutral with regard to jurisdictional claims in published maps and institutional affiliations.

Copyright: (c) 2021 by the authors. Licensee MDPI, Basel, Switzerland. This article is an open access article distributed under the terms and conditions of the Creative Commons Attribution (CC BY) license (https:/ / creativecommons.org/licenses/by/ $4.0 /)$.

\begin{abstract}
Ecovillages are collective projects that attempt to integrate sustainability principles into daily community life, while also striving to be demonstration projects for mainstream society. As spaces of experimentation, they can provide valuable insights into sustainability transformations. Through shared values and interpersonal connections, ecovillages possess collective identities, which provide a platform for enacting their ideals. However, many ecovillage residents question how to best enhance their role as models, resource centers, and pieces of a greater movement toward sustainability transformations, while simultaneously preserving their unique community and identity. In relation to the above, this paper addresses the questions: What can collective identity in ecovillage communities teach us about the objective and subjective dimensions of sustainability transformations? Furthermore, how can the perspective of collective identity highlight challenges for ecovillages for initiating sustainability transformations? Sustainability transformations encompass objective (behaviors) and subjective (values) dimensions; however, the interactions between these spheres deserve more scholarly attention. Using ethnographic data and in-depth interviews from three ecovillages in the United States, this paper reveals the value in collective identity for underscoring belonging and interpersonal relationships in sustainability transformations. Furthermore, the collective identity perspective exposes paradoxes and frictions between ecovillages and the societal structures and systems they are embedded within.
\end{abstract}

Keywords: sustainability transformations; ecovillages; collective identity; intentional communities

\section{Introduction}

Multiple scholars have called upon the necessity for societal transformations in order to address current sustainability challenges, such as spatial inequalities, poverty, resource depletion, climate change, ecological hazards, and food insecurity [1,2]. This so-called "transformative turn" in sustainability research attempts to address the unsustainable systemic roots in our society and confront different kinds of knowledge and experiences [3].

Ecovillages, or intentional communities (ICs), can be considered "frontrunners" and spaces of experimentation in sustainability transformations [4,5]. Intentional communities refer to communal living arrangements more broadly, with sub-categories also including religious communities and communes [6]. Ecovillages focus specifically on living sustainably and in a way that reduces their environmental impact [7]. The Global Ecovillage Network (GEN) is an umbrella organization which provides knowledge-sharing opportunities, as well as a database of different categories of communities, such as transition towns and indigenous and spiritual communities. While the database has recorded over 1000 ecovillage communities in the world and 109 registered in the United States [8], there are many more existing that are not registered. Ecovillage sustainable food practices, for example, have gained prominence in sustainability debates $[9,10]$, through centering food systems around local communities and environmental care [11]. Rather than being concerned with the "symptoms" of unsustainability, ecovillages also address its structural 
roots by reorganizing their labor systems, challenging capitalist notions of property, and confronting patriarchal structures-therefore classifying them as transformative or radical alternatives [12]. Despite their innovativeness, ecovillages are still under-researched in geography [13].

Transformations focus on upending business-as-usual and point to the drastic measures necessary for society to tackle global challenges such as climate change [14]. We align this paper with the transformational adaptation approach, which could be defined as a radical system change, challenging the status quo, and implementing new regimes $[2,14,15]$. We specifically contribute to discussions of how concrete behaviors and values can support sustainability transformations [16-18] as well as challenges for communities. Transformational adaptation especially "requires a cultural shift from seeing adaptation as managing the environment 'out there' to learning how to reorganise social and socio-ecological relationships, procedures and underlying values 'in here'" [2] (p. 88). Transformational adaptation is not solely concerned with sustainability indicators; rather, it is categorized into complimentary "inner" and "outer" dimensions [16,18,19]. The "outer" dimension refers to "objective" behaviors and practices, while the "inner" or "subjective" dimension refers to motivations, beliefs, and values, on an individual or collective level [18]. Recognizing both dimensions acknowledges humanity's role and responsibility in climate change responses [20].

Despite the growing interest in the subjective dimension of transformations and the wealth of research on the objective dimension, there is little understanding how these spheres interact $[16,21]$ Climate change will induce social and economic burdens that require a combination of awareness, engagement, and planning capacities [16], in subjective and objective realms. Greater insight into interactions across spheres can therefore bring perspective into addressing sustainability transformations, as well as recognizing "how humans both create and respond to change" [22] (p. 1). The aim of this paper is to better understand interactions between the subjective and objective dimensions of sustainability transformations, through the lens of collective identity.

Collective identity can be described as a sense of "we-ness" based on shared attributes, experiences, and culturally-dependent characteristics [23]. Composed of shared values and action in collective groupings [24,25], collective identity gives weight to both objective and subjective dimensions of transformations and can help explore how these dimensions simultaneously manifest [12]. Specifically, collective identity recognizes the role of social connectedness for taking action on shared ideals and ambitions. An emerging body of research recognizes the value of (collective) identity for sustainability transformations [12,26] and socio-ecological change [27]; however, the connection between collective identity and the objective/subjective dimensions of sustainability transformations has not yet been made.

The concept of collective identity has been thoroughly studied in the context of social movements $[24,25]$ and ecovillages [28,29], where it is found to be integral as a "dynamic force for change" [30] (p. 97). While collective identity in ecovillage communities can help motivate members to act on their sustainability-related values, such ambitions face challenges when attempting to initiate a sustainability transformation in both dimensionsnegotiating collective values and sustainable behaviors [28,29]. Ecovillage communities, which take on sustainability-related actions, based upon sustainability-related values, relate to both the subjective and objective dimensions of sustainability transformations [5]. Therefore, this paper situates ecovillages as a space to explore both dimensions of sustainability transformations. By also exploring challenges for initiating sustainability transformations, we aim to highlight potential tensions that can arise in communities.

Our central questions are: What can collective identity in ecovillage communities teach us about the objective and subjective dimensions of sustainability transformations? Furthermore, how can the perspective of collective identity highlight challenges for ecovillages for initiating sustainability transformations? Through a combination of in-depth interviews and participant observation carried out in 2018, this paper explores sustainabil- 
ity practices and collective identity at three ecovillage communities in the US, including Twin Oaks in rural Virginia, Los Angeles Eco-Village (LAEV), and Finney Farm in rural Washington State. This paper will first elaborate on the sustainability transformation perspective and connect transformations to collective identity. The empirical section will explore sustainability transformations in the ecovillages, and thereafter apply a collective identity lens to transformations in communities. We will end with a discussion drawing out the relevance of collective identity for the subjective/objective dimensions of sustainability transformation, as well as challenges that surface in ecovillages.

\section{Theoretical Framework}

\subsection{Sustainability Transformations}

Transformations encompasses alterations in physical forms and systems [31]. Unlike incremental adaptations, which have been criticized as insufficient for combating global challenges such as climate change, transformational adaptations have been defined by their large scale and intensity, novelty to a site or system, and ability to occur in or be transferred to different places [32]. Furthermore, transformations are "an internal shift that results in long-lasting changes in the way that one experiences and relates to oneself, others, and the world" [33] (p. 1). In this paper we employ and build upon O'Brien's [34] definition, which highlights three-tiers: (practical) concrete actions and interventions; (political) structures, norms, rules, and institutions; and (personal) values and worldviews. The outermost personal sphere can potentially influence the previous two spheres, shaping behaviors and institutional structures "from inside out" [33], and has been considered vital for sustainability transformations [35].

Sustainability transformations specifically aim to study the "dynamics, barriers, and processes that move systems in the direction of sustainability" [36] (p. 3). We conceptualize this "direction" of sustainability to include supporting "social needs and welfare, and economic opportunity are integrally related to environmental limits imposed by supporting ecosystems," [37] (p. 87), as well as steering values away from overconsumption, resource depletion, and social and economic injustices [38]. Through, for example, collective ownership of resources, ecovillages strive to collectively reflect upon and commit to sustainability ideals [39], and could provide insight into initiating experimental spaces of transformations.

In this paper we combine O'Brien's [34] transformation framework with the subjective and objective dimensions in Wilber's [18] All Quadrants All Levels (AQAL) model. We apply this updated model (see Figure 1) to the ecovillages studied, to help ground community activities in sustainability transformations theory. Wilber's [18] AQAL model designates the "I", "WE", "IT", and "THEY" dimensions of transformation. The IT (objective) and THEY (inter-objective) quadrants correlate to O'Brien's [34] practical sphere, concentrating on actions, skills, and behaviors, at an individual (IT) and collective (THEY) level. The I (subjective) and WE (inter-subjective) quadrants are comparable to O'Brien's [34] personal sphere, focusing on "inner" characteristics, such as values and worldviews, also at an individual (I) and collective (WE) dimension. The THEY and WE dimensions also relate to O'Brien's [34] political dimension, through their focus on collective systems, structures, and norms. Thus, the WE links to the political and personal spheres, as it represents both, collective framings, as well as how these are formalized in institutions. Combining both models provides a framework through which to position ecovillages' (objective) actions and (subjective) values, as well as how the communities relate to (mainstream) institutions, in their attempts to initiate sustainability transformations. 


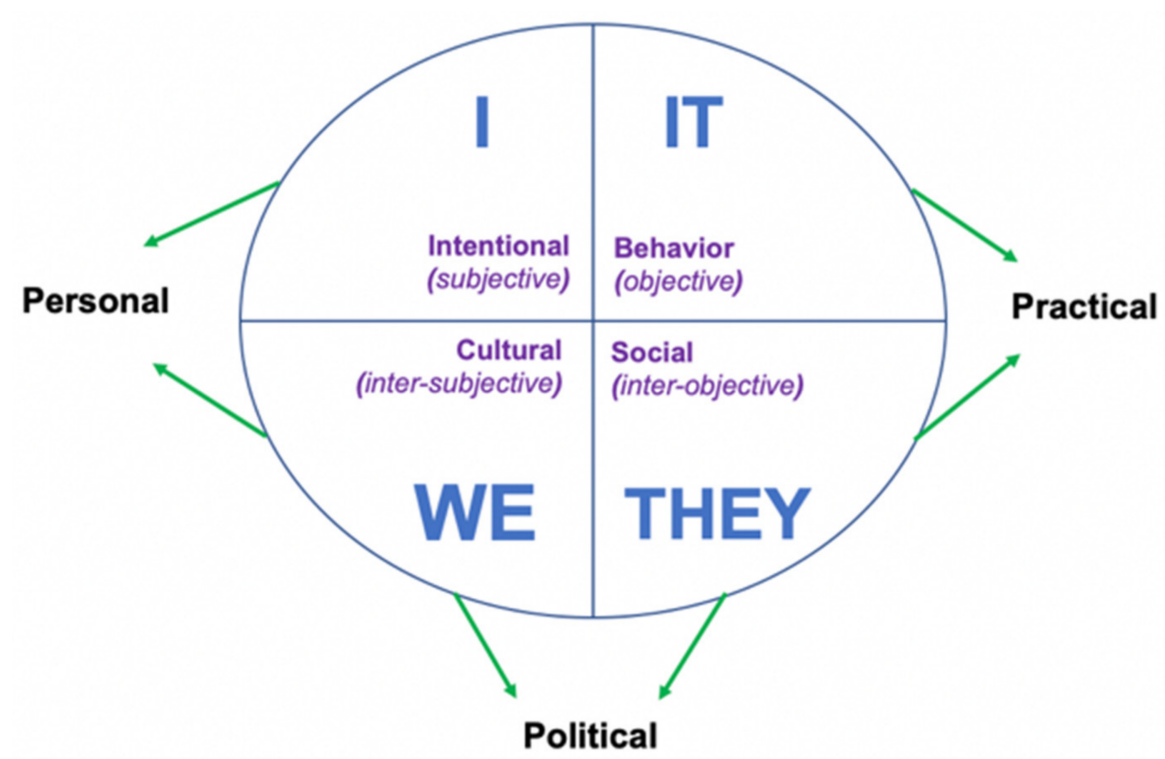

Figure 1. Operationalization of sustainability transformations, combining O'Brien's [34] transformation framework and Wilber's [18] All Quadrants All Levels (AQAL) model.

Ecovillage communities can help understand "on the ground" sustainable practices and how these are linked to the subjective dimension of transformation. The subjective dimension highlights internal changes of individuals and collectives, including changes of values, beliefs, and worldviews, through "deep learning" and creating new relations [3,33]. Exploring "subjective worlds" in ecovillages also helps to understand values, attitudes, and beliefs which lie at the root of our (unsustainable) systems $[33,40]$. Alongside system changes, sustainability transformations require perspective changes of the ways in which we interact with and conceive of the world-from one embedded in growth and consumerism, towards a paradigm of intentionality, supporting human and planetary health and well-being [40]. In ecovillages, the subjective dimension could materialize through a "deep experimentation with the self" towards "self-improvement, self-development, and/or self-transformation" [41] (pp. 396-397). In this context, gardening could be viewed as an example of a spiritual practice, connecting human / natural worlds and subjective/objective dimensions [41].

Interactions and alignments between the subjective and objective dimensions have been under-researched in transformations literature $[16,17,22]$. The greater focus on the objective dimensions has been argued to "downplay the importance of the subjective" [20] (p. 1). As found with resilience, objective factors (i.e., observable indicators) cannot sufficiently explain potential discrepancies, notably individuals' capacities to adapt and respond to risks [42]. Only together, can these dimensions understand climate change responses within the context of values and worldviews [20], therefore recognizing climate action as carried out by specific (human) agents [12,35].

Sustainable (food) practices in communities similarly connect to notions of autonomy and self-reliance [43], a potential venue through which ecovillages act upon their sustainability values. Ballard et al. emphasize how agency, or the capacity to act, is "not simply a personal or social construct, but occurs at moments, often fleeting moments, when individual and collective, subjective and objective factors come together" [16] (p. 14). Greater public awareness, for example, can help facilitate agency and involvement [44]. Agency not only helps activate the individual and collective but is necessary to carve out opportunities for acting upon global environmental change [45], and is often overlooked in systems perspectives-adjusting attention to "the who and why rather than the how and when" [35] (p. 258). Therefore, a combination of knowledge and self-responsibility could inspire individuals and communities to act, and connect objective and subjective dimen- 
sions of sustainability transformations. This paper will further explore how ecovillages connect their (sustainable) values and behaviors, through their collective identity.

\subsection{Collective Identity and Its Relevance for Transformations}

Through inspiring action around shared values, collective identity is a concept relevant for transformations $[25,30,46]$, and which has been linked to ecovillage communities [28,29]. Collective identity in social movements is identified via three main dimensions: cognitive frameworks, collective action, and belonging $[25,30]$, through which it is visible in subjective and objective dimensions [18].

Firstly, cognitive frameworks refer to shared meanings, enacted through community practices and behaviors [24]. These are similar to collective values and worldviews, and correlate to the subjective dimension of transformation, also as they mediate practices and "influence the construction of narratives and place identities" [19] (p. 166). Cognitive frameworks, championed by Alberto Melucci [25], emphasizes collective identity as a process of negotiation and understanding, allowing for nuances in meaning-making, rather than a singular set of beliefs [24]. Ecovillage values support ecological and social sustainability and connections to the natural world [5]. Secondly, collective action actively manifests collective processes [30,47], boosting an individual's collective impact [25]. Collective action is reflected in the objective dimension of transformation, through practices and behaviors. Ecovillages exhibit collective action, shifting environmental stewardship and action from the individual to the collective [48]. Lastly, belonging refers to a shared sense of connection, and is reinforced through shared practices and values [47]. Belonging is comparable to social consciousness, which is described as "awareness of being part of an interrelated community of others" and has been shown to contribute to transformations, through heightened pro-social behaviors [49] (p. 21). Interpersonal connections are essential for uniting collectives and generating commitment among members [50].

Collective identity in ecovillages potentially provides insight into interactions between subjective and objective dimensions of sustainability transformations. While practices and behavior change are more visible, "a move toward activism is 'more grounded in one's sense of connectedness, one's identification with morality, and one's sense of larger meaning and purpose'" (Berman 1997, as quoted in [49], p. 21). Therefore, collective identity potentially emphasizes interpersonal connections for prompting social change. Belonging, empathy, and trust recognize emotional experiences for informing behavior change, and have been linked to climate change responses $[26,27]$. Ecovillages can potentially motivate sustainability action, through such community bonds, which this paper will explore through collective identity.

However, collective identity is not to be romanticized in communities. Gamson reminds us that the "merging of individual and collective selves is rarely if ever complete ... however much we may identify with a movement, we have other sub-identities built around other social roles" [50] (p. 45). This points to challenges when linking collective and individual identities-a tension also seen in ecovillages [48]. Collective identities are pluralistic and not solely based upon individual identities [47]. Blythe et al. [15] similarly cautions assuming transformation will be universal across social groups. It is therefore crucial to understand community motivations and effectiveness in enacting change-in subjective and objective realms.

Identities formed in relation to difference [30] present a paradox for groups attempting to initiate wider-scale change. This contradiction is relevant in ecovillage communities, which define themselves relative to the mainstream, while attempting to influence it $[28,29]$. Westkog et al. [29] and Ergas [28] research nearby mainstream communities relative to the creation of collective identities at ecovillages. When examining interactions between ecovillages' collective identities and dominant structures, Ergas [28] confirms such paradoxes, finding that communities adapt to the mainstream society while also challenging structures in their everyday actions. In examining relations between the ecovillage and its local community, Westkog et al. find the ecovillage is "a project and locus for identity construction, 
heavily informed through interaction with the outside world" [29] (p. 14). These studies caution closing (identity) gaps between ecovillages and mainstream communities, which "would also mean losing its ability to promote an alternative to mainstream lifestyles" [29] (p. 17). We expand upon these papers through employing collective identity as a lens to understand challenges encountered by ecovillages for sustainability transformations.

\section{Methods and Case Descriptions}

\subsection{Methods}

\subsubsection{Case Selection}

This study researches collective identity and sustainability transformations at three ecovillages in the United States-Twin Oaks in rural Virginia; LAEV in Los Angeles, California; and Finney Farm, in rural Washington state. In order to reflect the diverse American landscape, this research includes communities located in the rural and (overall) conservative South, urban (progressive) Southern California, and rural (environmentalist) Pacific Northwest (see map, Figure 2).

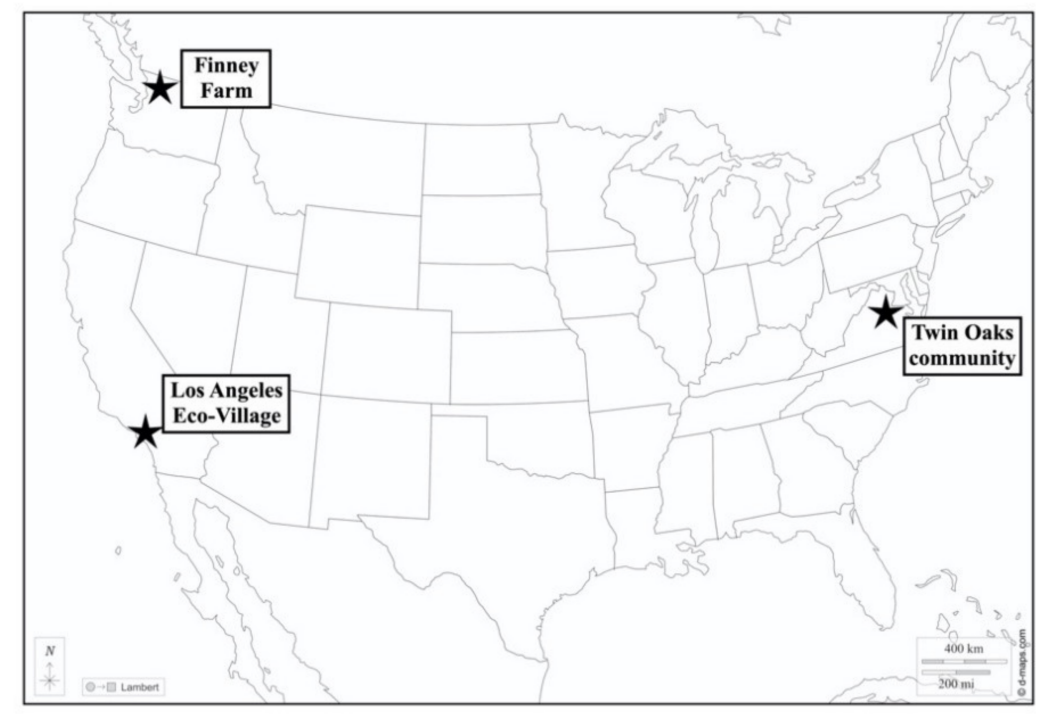

Figure 2. The three ecovillages studied with their locations in the United States (source: author).

These ecovillages were chosen based on how established each community was-a combination of their longevity, number of members, and web presence [51]. The case selection prioritized communities that exhibited practices around sustainability, within the community, and with external communities-characteristics relevant for sustainability transformations. Two prominent online directories, the Foundation for Intentional Community [52] and the Global Ecovillage Network [8], were utilized to search for and select the communities. Ecovillages being listed in these indexes also indicate connections or the wish to be connected to broader community networks. A search resulted in 21 relevant ecovillages, which was narrowed to three, based on the above criteria and those willing to participate. Table 1 presents the three selected in terms of size, location, and length of establishment.

Table 1. List of ecovillage communities.

\begin{tabular}{llll}
\hline Characteristics & Twin Oaks & Los Angeles Eco-Village & Finney Farm \\
\hline Location & Virginia, rural & Los Angeles, CA, urban & Washington State, rural \\
Founding year & 1967 & 1993 & 1989 \\
Number of residents & 100 & 40 & 8 (plus volunteers) \\
\hline
\end{tabular}


The aim of the research was originally to focus on the ecovillages' sustainable food practices and potential for wider-scale change. However, when inner struggles reappeared in the data analysis, collective identity inductively emerged as a pressing issue in the communities and as valuable to explore further. It became evident that, across all the ecovillages studied, communities' aspirations for wider-scale change conflicted with communities' desire for intimacy and for maintaining their unique identity. Thus, collective identity was found to be relevant, not only for explaining how communities operate, but also for making sense of barriers residents experienced with mainstream society. After this trend resurfaced, the first author analyzed interview and observation data, with codes based on the operationalization of collective identity detailed above and the objective/subjective dimensions of transformation, using NVIVO coding software.

\subsubsection{Methods}

This study utilizes ethnographic methods to research three ecovillage communities, employing participant observation and in-depth interviews. Ethnography is celebrated as a means through which to research climate change (e.g., [39,53]). As stated by Roncoli et al. [54], ethnography takes advantage of anthropologists' ability for "being there" to connect different (local) understandings and ways of knowing. Tsing [55] argues that ethnography can analyze spaces or "frictions" of difference, between the local and global. Therefore, anthropologists play a role in looking at place-based research in communities and connecting these to globally-focused discourses, both necessary for global challenges such as climate change [53]. Ethnography is suitable for researching ecovillages as these communities could be considered as living an "examined existence" [56] (p. 152), acting upon elements to intentionally change from the mainstream. Studying ecovillages through an ethnographic lens reveals a "cultural critique" [57], illustrating the social world surrounding daily practices [39]. Therefore, ethnography reveals nuances and challenges surrounding communities.

The first author conducted ethnographic fieldwork, staying at each selected community for one month during the summer, in 2018. During each stay, she volunteered in work areas focused around daily life and food, such as gardens and kitchens. The author plugged into visitor activities, more formally at Twin Oaks and Finney Farm, and when opportunities arose at LAEV (e.g., helping organize a community conference). Observation notes documented community practices, from work areas and daily life, including passing conversations, events, and reflections, in a semi-structured diary format.

Additionally, the first author conducted 37 in-depth interviews with community members and visitors, with 16 at Twin Oaks, 11 at LAEV, and 10 at Finney Farm. Interviewees were 17 to 81 years old, and an average of 43 years old across all communities. 16 participants identified as male $(43 \%), 17$ as female $(46 \%)$, two as agender or neutral $(5.5 \%)$ and two who preferred not to answer (5.5\%). Participant selection hinged upon their role in the community, with those in leadership or organizing roles (board members, founders, and long-term members) specifically sought out. All interviewees signed informed consent forms, stating that they participated voluntarily. Names of all interviewees have been changed to pseudonyms, unless the interviewee specifically requested their real name to be used. All research conducted (including informed consent and data management) has been approved by the research ethics committee of the authors' home institution.

Interviews helped understand participants' interpretations of their community's identity and community strategies for transformation. Interviewees' honesty and openness was especially valuable for unpacking contradictions and (inner) conflicts between mainstream lifestyles and their individual beliefs and community values.

\subsection{Case Descriptions}

\subsubsection{Twin Oaks}

Twin Oaks comprises 100 adults and children, located in rural Virginia. It is the oldest of the communities researched, with roots from earlier communes in the 1960s [58]. Its 
formation was inspired by the structured labor system in B.F. Skinner's Walden Two, based on members completing $42 \mathrm{~h}$ of work, still existing today [59]. The community's labor distribution system values all work-in income-earning and domestic areas-equally, and exemplifies Twin Oaks' egalitarian values. Twin Oaks' economic endeavors comprise of a tofu business, hammocks, seed growing, and book indexing. While community businesses ensure their financial stability, the majority of labor is household work, such as gardening, tending to the dairy cows, cooking, and cleaning. All members receive their basic needs, including food, housing, healthcare, and a monthly allowance of \$100. Remaining income is reinvested in the community.

Throughout most of the year, Twin Oaks hosts a three-week visitor program. In this program, visitors plug into labor areas and follow orientations to learn about community life-including orientations about the legal system, the labor system, and values. The visitor program helps to educate those interested in the life of the community, as well as supports potential members to explore whether living in the community is a good fit. Twin Oaks is also a member of a larger communal, income-sharing network in North America, the Federation of Egalitarian Communities (FEC). The FEC provides resources to communities, including access to an emergency health care fund, recruitment support, and labor exchanges [60].

Twin Oaks is made up of a range of ages, also including young children, teenagers, and older adults. One of the resident houses is specifically built to accommodate older generations, to make it possible for community members to live their last days on the property. While this research did not conduct any surveys on class, race, or education level, many residents were observed to hold a university degree. Twin Oaks recognizes the low number of people of color (POC) in their community, which has remained consistently under 10 and has led to difficulties for these members in feeling heard in their community and in the broader community movement. The ecovillage is taking action through the initiation of a group of racial equity and advocacy leaders-a team responsible for leading community meetings on racial justice and implementing policies towards racial diversity and education [61].

\subsubsection{Los Angeles Eco-Village}

Los Angeles Eco-Village (LAEV) is located in one of the densest and most diverse urban neighborhoods in Los Angeles, Koreatown. Comprised of former apartment buildings, LAEV's property includes 40 housing units across three buildings, a lush courtyard and front gardens, and shared workspaces and equipment (i.e., tool sheds). LAEV also helps operate the neighborhood "Learning Garden," an educational garden and example of ecovillage partnerships with neighborhood organizations within their local community. Such efforts align with the ecovillage's vision of creating an eco-neighborhood, with long-term goals including becoming a car-free neighborhood.

Additionally, LAEV participates in larger networks, including the Global Ecovillage Network, as well as the more local Los Angeles Intentional Community Summit. Both are opportunities to discuss working within their community, as well as wider knowledge sharing.

While LAEV was found to be the most racially diverse of the three communities, approximately two-thirds of their members were observed to be white. Ecovillagers' profiles differ compared to their neighborhood, which mostly consists of residents with a Korean or Central/South American background. That being said, community members are aware of this difference and actively engage with their neighbors and attempt to overcome social and cultural barriers, for example bringing instruments for a weekly jam session on the sidewalk - an occasion many neighborhood children were observed to join. Many members at LAEV were also witnessed to be involved in professions relating to sustainability - either larger international projects (e.g., non-governmental organizations) or local initiatives (e.g., bike advocacy and water conservation). The majority of members were observed to be in their 30-40 s; however, there were also a few young children and older residents (the eldest being 81). 


\subsubsection{Finney Farm}

Finney Farm accommodates eight residents and a revolving door of volunteers and interns. The community was founded in 1989 by self-described anarchists, with roots in environmental activist movements, such as Earth First! The group established the Salmonberry Community Land Trust as the ecovillage's legal body.

Located in rural Washington state, Finney Farm consists of 105 acres (42.5 hectares), 90 (36.4 hectares) of which are second-growth forest under conservation. The remaining developed area of the property includes scattered tiny house cottages (where residents live), approximately five acres of communal garden areas, a repurposed barn, and a larger community house. Today, the community members of Finney Farm honor their activist roots while priding themselves on their strong relationships with nearby communities.

Finney Farm connects to larger networks through local community organizations (e.g., a radio station and schools), as well as internships and educational opportunities through the websites WWOOF, HelpX, and WorkAway. Many members, who eventually come to live at the community, are introduced to Finney Farm through these educational outlets.

The age composition at Finney Farm was found to be relatively young and included families, but no-one over the age of 50 . While community members recognized the importance of (racial) diversity in their community, their small population perhaps limited the extent to which this could be achieved. Overall, community members worked either in education or construction, with many commenting that it was difficult to find employment in their rural area.

\section{Results}

\subsection{Sustainability Transformation in Ecovillage Communities}

Throughout all the ecovillages researched, three transformation dimensions emerged, aligning with O'Brien's [34] spheres of transformation. The original focus of this research, around food sustainability, provided prominent examples of food-related sustainability practices, for example organic food production and consumption. This section will outline how the ecovillages illustrated potential and inspiration for sustainability transformations.

\subsubsection{The Practical Sphere}

First, we witnessed localized strategies, or ecovillage actions for their immediate community, correlating with O'Brien's [34] "practical sphere". For example, all ecovillages attempted to be "models" for mainstream society, to inspire further action. This included growing and processing their own food (for self-consumption and distribution), as well as hosting public tours and conferences-examples witnessed in all ecovillages. All the ecovillages studied recounted interactions with their immediate neighbors. LAEV, for example, hosted a number of local action groups (e.g., around immigration rights and bicycle activism), DIY grey water installation, and bicycle maintenance workshops. Finney Farm described building community gardens at schools and prisons and distributing free seeds. Twin Oaks welcomed many visitors onto their property, including through their Communities Conference, one of three summer conferences meant to educate and network those interested in communal lifestyles. These numerous activities work towards the communities' goals of education and outreach regarding their sustainable alternative lifestyle. Sustainability practices also involved taking responsibility and asserting selfreliance. For example, while communities praised the idea of recycling, many did not trust the efficiency of municipal recycling programs, and, instead installed composting toilets or composted food scraps. Thus, communities questioned mainstream sustainability definitions and sought their own solutions.

The three sites also differed in approach. Twin Oaks' members described themselves as not actively advertising and rather becoming "grounded in the reality of [their] own land," focusing on big picture goals, as stated by Community and Visitor Outreach Correspondent, Veronica. LAEV's urban context was described by participants as fundamental to the project's outreach and accessibility goals. Their dense neighborhood and the city's high 
concentration of international press give LAEV "the potential to influence the whole world from this little two block neighborhood" as stated by Lois, LAEV's founder. LAEV's urban setting exposes and, arguably, more directly confronts them with the status quo in their everyday activities. Ecovillage members recognize the importance of their daily sustainability practices for creating impact outside their community.

\subsubsection{The Political Sphere}

The political sphere materialized through attempts to influence structures in and outside of their community [34], including strategies for enacting systemic changes (e.g., policy), expanding (e.g., buying land and supporting other ICs), and incubating projects (e.g., sustainably-sourced businesses). For example, Twin Oaks assisted revising the US 501(d) tax status. While the 501(d) is typically applied to religious or apostolic communities, Twin Oaks broadened the definition to also include granting income-sharing communities as tax exempt. This policy amendment set the precedent for other ICs to apply for this status, and allowed a (financial) "sense of security ... increas[ing] collective prosperity," as noted by the Legal Manager, Pat. This tax exemption is an example of how Twin Oaks creates lasting effects in (mainstream) systems and opens legal capacities and opportunities for other (income-sharing) communities to be more autonomous [62].

LAEV confronted municipal policies through "pre-legal" activities, that is, projects that are not illegal, but also not yet legal. Many pre-legal activities (which were legalized)including mulching, graywater collection, and backyard chickens-support sustainable (food) systems, through reducing harmful external inputs [11]. However, pre-legal activities must be enacted with caution, as blindly acting upon one's values could result in unjust and unsustainable practices. In the political sphere, ecovillages played a role shaping policy and community action, through influencing change from the local to the national scale.

\subsubsection{The Personal Sphere}

Lastly, ecovillages supported transformative changes through members' experiences and motives, aligning with O'Brien's [34] "personal" sphere. Individual residents recognized their "cultural baggage" — that is, how they are shaped by past experiences in mainstream society, despite being discontent with it. After time in their ecovillage, interviewees acknowledged a mental shift, in their own lives, or in others. Hank, a resident of Finney Farm, reflected:

"Before I lived here, I wanted the same as everybody else, the "nice things" in life.

But living out here I realized, there are more important things ... like, reducing your carbon footprint."

By "nice things", this interviewee refers to material wealth and consumer goods, promoted by mainstream society. Instead of seeing their lifestyle as "backwards" (e.g., no indoor plumbing and limited electricity), Hank learned to shift his perspective to appreciate a more intentional and sustainable lifestyle (e.g., awareness of water and energy usage). Living at Finney Farm helped reframe Hank's experiences in a larger context, and to understand how his priorities and values have changed. Such a sentiment was echoed in other communities.

In the next section we will revisit ecovillages' attempts to support transformation, through the lens of collective identity.

\subsection{Collective Identity Supporting Sustainability Transformation}

Below, this paper will connect the three dimensions of collective identity (cognitive frameworks, collective action, and belonging) to sustainability transformation practices at ecovillages. It should be noted that overlap was found across sub-categories of collective identity. 


\subsubsection{Cognitive Frameworks and Values}

Cognitive frameworks refer to shared values and worldviews and connect to the subjective dimension of sustainability transformations. Shared values materialized formally in community documents, for example in bylaws and articles of incorporation, which were drafted upon communities' formation and direct their development. Veronica, who leads the values orientation at Twin Oaks, stated that their bylaws:

"[Lay] out, all different aspects of living, interpersonal relationships, sustainability. Those are two very big ones ... if people want to make changes, we can make changes, and it's sort of tethered to those cultural ideas."

Therefore, those two elements (interpersonal relationships and sustainability) help to map Twin Oakers' behaviors. Guiding documents also outlined the ecovillages' aims for influencing mainstream society, for example, the creation of new egalitarian communities (at Twin Oaks), or education and outreach (at Finney Farm), indicating their intention towards (wider) sustainability change. Though all communities described collective values, behaviors were not specified in written documents. Jamie, a Finney Farm member, described their bylaws as a guide, allowing flexibility in community endeavors. She elaborated,

"If our ideas [in the bylaws] are about stewardship, being a homestead, and doing social and education outreach, then our all of our actions need to be in line."

Therefore, the community traces their actions back to their founding ideas and values. Finney Farm works towards strengthening their food system, as a means to achieve community goals, connecting community values with action. Twin Oaks' policies stated a similar construction. Thus, ecovillages develop frameworks where appropriate sustainable behaviors are expected to follow their communities' sustainability values.

Shared values were not consistent within ecovillages. A Twin Oaks member, Veronica, distinguished between "stated" versus "lived" values-what community members say versus what they do. The topic of buying and eating factory-farmed meat, in particular, raised questions and conflict internally. Veronica elaborated, saying:

"For some people, their stated values match up, for some people they match up some of the time, and for some people, their stated values never match up. So, with this, my stated value is I want to eat home grown healthfully ... and my lived value is I'm only human and I only do that a certain amount."

Therefore, when the food buyers purchase factory-farmed meat, contradicting the values of the community, Veronica finds that "it's not respectful of the bigger reality of the community and our values" and therefore abuses the responsibility to make decisions which do align with Twin Oaks' values. This conflict also resurfaced in other interviews. While no community-wide solution was found, individuals reacted to the situation in their own way. Penelope, the ex-garden manager, posted a note on the forum in the community area, which resulted in some diminished purchasing (according to interviewees). Jessica turned her efforts to working with the cows and the dairy program, hoping local meat production would reduce meat purchased from factory farms. A number of members, including Veronica and Penelope, also mentioned the necessity to "pick their battles." The inevitability of disagreements therefore points to the requirement of transparent communication, as well as a certain degree of flexibility. For example, many members stated that they simply made the personal choice not to eat factory-farmed meat, as it was labelled when served in community meals.

Across other communities, interview participants were aware of subtle and unintentional barriers, creating a self-selected group and preventing communities from diversifying. Sara, a member at LAEV, described:

"Living in an intentional community, you're ultimately living in a bubble of likeminded individuals. As far as I know, there isn't anybody too outside of my political beliefs here." 
While this "bubble" helps the community achieve goals around sustainability within the ecovillage, it poses challenges when trying to impact those that do fall outside such worldviews. For example, unintentional exclusivity could present hierarchies and social barriers for external communities [13]. Therefore, aligning values can connect members, while also preventing communities from diversifying. For ecovillages hoping to initiate sustainability transformations, this might require their "bubble" to burst.

\subsubsection{Collective Action}

Collective action refers to community activities, carried out in line with community values. While collective action is linked to objective dimensions of transformations (through activities and behaviors), it extends across objective and subjective dimensions. Participants across sites recognized that their community promotes activism around their (sustainability) values, for example, building community gardens. LAEV member Ari indicated:

"[Environmental and social sustainability and justice] are all notions that I feel that I've always been aware of and found very important but through being here in community ... I feel that I've gained access to a language or a structured way to employ this."

For this participant, the ecovillage presented a unique site to explore a spectrum of participation opportunities.

Collectivism strongly linked sustainability action and values across ecovillages and was viewed by community members as a means to disrupt individualistic ideals. Throughout interviews, residents connected these values as a means to challenge the status quo, that is, a capitalist system based on growth and exploitation. Twin Oaks member Veronica, stated:

"In mainstream American culture we are not taught cooperation ... we are taught individualism ... we all have what I call a cultural hangover ... of what we are conditioned in mainstream culture, and the more you live this way, the more your worldview shifts to be more cooperative and egalitarian."

Collectivism, as emphasized in communities, challenges mainstream cultures and contributes towards sustainability - a value also documented in other studies on sustainability transformations [12]. The above quote stresses the "protected" space for community ideals to materialize as behaviors and the role of the physical and social environment for transformations. Multiple respondents described the United States and LA as especially individualistic and promoting an unsustainable lifestyle. In their bounded, collective space, ecovillages distinguish from mainstream conventions and redefine sustainable behavior change in their specific context.

Community decision making illustrates how values of collectivism and cooperation link to community-level action. Participants described decision making as thinking at a "community level," instead of at the level of individual needs or goals. An LAEV resident, Sara, described the process as follows,

"Making a decision together, is miraculous ... it's like "is it good or bad for the community?" "Is it good or bad for me?" the second, does not have a place here.

"Is it good or bad for the community?" does have a place here."

Community meetings offer essential opportunities to discuss viewpoints and make shared decisions, prioritizing community values and connecting those to concrete actions. Through decision-making, residents experience what is at the core of community life and "what it means to cooperate" (Yolanda, LAEV interview). Embedding themselves in the ecovillage, members learn about others' ideals as well as actual practices. Opening discussions point to flexibility in communities' collective identity. Decision-making fosters the exchange of knowledge, and, in turn, can help members hold one another accountable to their values and practices, thereby connecting across objective and subjective dimensions.

Ecovillages' collective actions included participation in rallies and protests, and, more prominently, alternative means of organizing their lives, through labor systems, 
sharing space and resources, and committing to sustainability principles. Participants emphasized that shared values of cooperation and collectivism not only stood in contrast to the mainstream, but also indicated ecovillages' intention to challenge such systems, and were found to be integral to ecovillages' identity.

\subsubsection{Belonging}

The element of belonging brought together the above aspects of collective identity, relevant across objective and subjective dimensions of sustainability transformations. Across the communities studied, interviewees stressed joining their ecovillage for a sense of belonging and interpersonal connections. Timothy, a 23-year-long member at Twin Oaks, stated,

"A number of people come to community [and] ... don't think about the fact that they're also creating a worker owned cooperative ... Their focus is the ... relations they have with each other."

This quote summarizes how connection and belonging enable and facilitate collective action, within and outside their community. Ecovillage food practices often provided a space for participation and community bonding, around shared values [12]. Long-time Finney Farm member Jamie remarked,

"Food ... plays a large role because it's where we gather. It's ... ways in which we connect with each other and, if you're gardening, it's like you're working together, and you're growing these things which is very bonding and collaborative ... we have this extra layer here because we're doing this bigger, different thing."

The "bigger, different thing" refers to community education and food access outreach programs. Performing sustainable food practices reinforces collective values around environmental care and offers opportunities for community members to exchange knowledge and build interpersonal relationships. Food practices were a bonding mechanism, as well as a behavior in itself, contributing to sustainability.

However, exclusion in interpersonal relationships presented a challenge for all ecovillages. Lois of LAEV stated, "conflict and divisiveness took their toll on me, and others in the community," pointing to the importance of managing interpersonal relationships within the community, before considering the role of ecovillages in greater-scale transformations. Communities attempted to intentionally address these issues through trust-building community retreats and conflict resolution committees.

To summarize 4.2, while multiple values and identities existed across communities, ecovillages' collective identities surfaced from a desire to "do things differently." Connecting ideals to concrete actions, community structures facilitate cooperation in the community, linking collective values and behaviors. Despite interpersonal conflicts, a sense of belonging strengthens communities and their collective power.

\section{Discussion: Implications for Transformations to Sustainable Societies}

\subsection{Collective Identity and Transformations}

Collective identity is relevant for connecting discussions of sustainability transformations to ecovillages and sustainability-focused initiatives [2,34]. As detailed in the introduction and theory sections, the more fundamental and lasting transformations "happen" when the underlying values, beliefs, and ideals shift in a way to support certain practices and behaviors. While the aim was not to prove that ecovillages as such are transformative, the community practices of the ecovillages studied reveal them as a source of inspiration and experimentation for transformative change.

Collective identity revealed mechanisms that bring together objective and subjective dimensions of sustainability transformations. While shared values in communities largely corresponded to the subjective dimension, and collective action to the objective, the element of belonging was found to contribute to understandings across objective and subjective dimensions. Feelings of belonging have been pointed to as a source of motivation for 
collective action [63], which was also seen in this research to bring community members together, to act upon shared ideals. Belonging highlights the role of emotional dimensions of sustainability transformations, such as empathy, which has been found to contribute to sustainability when individuals hold inclusive identities [26]. Belonging could thus be seen to play a role in facilitating interactions between objective and subjective dimensions of transformations.

The importance of belonging was especially witnessed and understood through food practices in ecovillage communities through bonding over mealtimes and garden work. Food was found to be valuable for motivating members to enact practices around sustainability and self-reliance, and engage with their greater community. Food provided a platform to experiment with sustainability transformations, connecting shared values to onthe-ground practices. It has potential to act as "both an unexplored means to change and an end in itself" [40] (p. 211). Reorganizing (food) systems towards sustainability, (re-)shapes communities' lives, therefore also working towards an alternative to the mainstream $[43,64]$.

The focus on collective identity in ecovillages underlines the societal drivers of radical change [35]. For example, while disagreements surfaced from variations among individuals' values, the desires for social connections motivated members to overcome such discrepancies. Ecovillages' shared willingness to "do things differently" could be connected to an "oppositional consciousness" [65], that is, the collective capacity of groups to "attempt to create alternatives to the hegemonic system" [12] (p. 754). This could be a way in which ecovillages' shared perspective connects their values to action relevant for transformations. The shared experiences seen in collective identity was therefore found valuable to help form narrative pathways [66] in communities, with values and worldviews framing debates [36], towards transformative futures.

\subsection{Sustainability Challenges: Frictions with the Mainstream}

Viewing ecovillages through the lens of collective identity, two challenges for communities surfaced: maintaining their internal community cultures and identities and remaining open and accessible for interaction with the mainstream. These tensions largely stemmed from community members interacting with mainstream actors, thereby indicating that challenges lie in navigating sustainability transformations relative to the societal structures and systems they are embedded within. Cases in this research align with Escribano et al., who found ecovillages to be "more dependent on the world they intend to change than they would like," often out of the necessity of operating within a market-based society [4] (p. 12). Collective identity could result in "the creation of boundaries that insulate and differentiate a category of persons from dominant society" and while it may facilitate groups, such as ecovillages, to enact and trigger change, such groups often remain isolated based on their otherness [46] (p. 122). Intentional communities, Sargisson argues, "need this self-estrangement in order to self-identify" [41] (p. 417). Participants in this research similarly reported hesitation or even frustration when attempting to reach out to their more "mainstream" neighbors. Living in an ecovillage and engaging with outside communities necessitates communicating with those that share, but also differ from the community's values and worldviews. Community members were aware of differences and their own tendency to operate in a "bubble". Overcoming the social and cultural barriers between ecovillage communities (and collectives more broadly) and mainstream society points to a challenge in addressing sustainability transformations.

Researchers have recently documented increased interaction between ecovillages and the mainstream, resulting in decreased differences between (more sustainable) ecovillage lifestyles and neighboring communities, and the diluting of ecovillage values and practices $[29,48]$. Ecovillages in this research commented that their community values have been watered down, especially since the proliferation of the internet and "sustainability" in the mainstream. Ecovillages must reach a balance between opening up to mainstream society and preserving their community identity, perhaps with what Sargisson calls, boundaries that are "punctured and kept porous" [41] (p. 417). Maintaining values and worldviews 
and connecting them with sustainable practices and behaviors are vital for ecovillages as well as for sustainability transformations, in order to lead a change "from the inside out" $[33,40]$. For ecovillages, the challenge lies in keeping their (sustainability) practices from being co-opted by mainstream influences, while, simultaneously, being adaptive and open to avenues to engage with their local communities.

\section{Conclusions}

Our aim in this paper was to explore (1) what collective identity in ecovillage communities can teach us about the objective and subjective dimensions of sustainability transformations, and (2) how collective identity highlights challenges for ecovillages for initiating sustainability transformations. We found that collective identity underscores belonging and interpersonal relationships for sustainability transformations in the ecovillages studied. Furthermore, objective and subjective dimensions were visible in how values, such as collectivism and environmentalism, are translated into practices. Ecovillages in this research illustrate how values can be cultivated alongside behavioral change. Viewing ecovillages through the lens of collective identity foregrounds their defined ideologiesthe ways in which intentionality in such communities guides the "how" and "why" of their actions.

Collective identity was found useful for highlighting barriers towards sustainability transformations in the ecovillages studied. Collective identity informs how communities attempt to differentiate themselves from mainstream society, despite being confronted with pressures to adapt to it. While ecovillages were previously concerned with "escaping" technology and maintaining community ideals and autonomous practices [58], today we witness a rapid evolvement of community identities and cultures. Despite the prevalence of topics such as sustainability and feminism in mainstream society, we encourage a critical eye around the co-opting of values, and examining practices and values not adopted by the mainstream. Confronting power relations is essential for tackling environmental and social challenges in sustainability transformations, such as intersectionality in communities [12]. Diversifying ecovillages from their well-established homogeneity (white, middle class, and highly-educated) [67], for example, is a vital step to avoid replicating privileged societies and to initiate a larger movement [39], where collective identity could be a critical investigative tool [68].

Ecovillages have potential as valuable sites of experimentation for sustainability transformations [5,28,29], and provide policy makers an example for transformations towards sustainability. However, economic challenges, such as high rent and costs of living [4], necessitate opportunities and resources, such as community land trusts (seen at LAEV and Finney Farm), to make (physical) space for urban and rural initiatives. Localized projects provide insights into meeting (local) needs and how transformative change emerges "from below" [12,51]. We therefore encourage researchers and policy makers to support such radical collectives for transformations towards sustainability [12]. Transformation is "concerned with the wider and less easily visible root causes of vulnerability" [2] (p. 86). Acknowledging fringe projects could unveil their potential as breeding grounds for experimental practices [41] and identify gaps in our unsustainable society.

There were several limitations in this study. Firstly, only three ecovillages were researched for this paper, all of which were based in the United States. Therefore, the findings cannot be generalized to all ecovillage communities. Secondly, the research period lasted only one month in each community, relying especially on interview data. This provided a limited snapshot of the ecovillages' identity —one that did not span across the community's existence, but rather only what was witnessed during the research period. A study with more ecovillages, across a longer period of time, could be a valuable contribution for future research.

Ecovillages face challenges in preserving their fundamental values while also achieving their desired sustainability impact. Collective identity proved useful for highlighting 
how community bonds enable the connection of community values and practices, while initiating sustainability transformations.

Author Contributions: Conceptualization, C.U. and L.H.; methodology, C.U., L.H. and E.-M.T.; software, C.U.; validation, C.U., L.H. and E.-M.T.; formal analysis, C.U.; investigation, C.U.; resources, C.U., L.H. and E.-M.T.; data curation, C.U.; writing-original draft preparation, C.U.; writingreview and editing, C.U., L.H. and E.-M.T.; visualization, C.U.; supervision, L.H. and E.-M.T.; project administration, C.U.; funding acquisition, C.U., L.H. and E.-M.T. All authors have read and agreed to the published version of the manuscript.

Funding: This research received no external funding.

Institutional Review Board Statement: The study was conducted according to the guidelines of the Declaration of Helsinki, and approved by the Ethics Committee of the University of Groningen, approved on 3 April 2018.

Informed Consent Statement: Informed consent was obtained from all subjects involved in the study.

Data Availability Statement: The data are not publicly available due to confidentiality promised to research participants.

Acknowledgments: We would like to thank all research participants for donating their time and energy to this research project.

Conflicts of Interest: The authors declare no conflict of interest.

\section{References}

1. O'Brien, K. Global environmental change II: From adaptation to deliberate transformation. Prog. Hum. Geogr. 2012, 36, 667-676. [CrossRef]

2. Pelling, M. Adaptation to Climate Change: From Resilience to Transformation; Routledge: London, UK, 2010.

3. Dentoni, D.; Waddell, S.; Waddock, S. Pathways of transformation in global food and agricultural systems: Implications from a large systems change theory perspective. Curr. Opin. Environ. Sustain. 2017, 29, 8-13. [CrossRef]

4. Escribano, P.; Lubbers, M.J.; Molina, J.L. A typology of ecological intentional communities: Environmental sustainability through subsistence and material reproduction. J. Clean. Prod. 2020, 266, 121803. [CrossRef]

5. Pisters, S.R.; Vihinen, H.; Figueiredo, E. Inner change and sustainability initiatives: Exploring the narratives from eco-villagers through a place-based transformative learning approach. Sustain. Sci. 2020, 15, 395-409. [CrossRef]

6. Meijering, L.; Huigen, P.; van Hoven, B. Intentional communities in rural spaces. Tijdschr. Econ. Soc. Geogr. 2007, $98,42-52$.

7. Gillman, R. The ecovillage challenge. Context 1991, 29, 10-14.

8. GEN. Ecovillage Projects; GEN: Moray, Scotland, UK, 2021; Available online: https://ecovillage.org/projects/ (accessed on 30 June 2021).

9. Brombin, A. Faces of sustainability in Italian ecovillages: Food as a 'contact zone'. Int. J. Consum. Stud. 2015, 39, 468-477. [CrossRef]

10. Ulug, C.; Trell, E.M.; Horlings, L.G. Ecovillage Foodscapes: Zooming in and out of sustainable food practices. Agric. Hum. Values 2021, 1-19.

11. Blay-Palmer, A.; Koc, M. Imagining Sustainable Food Systems: The Path to Regenerative Food Systems. In Imagining Sustainable Food Systems: Theory and Practice; Blay-Palmer, A., Ed.; Routledge: London, UK, 2010; pp. 168-186.

12. Temper, L.; Walter, M.; Rodriguez, I.; Kothari, A.; Turhan, E. A perspective on radical transformations to sustainability: Resistances, movements and alternatives. Sustain. Sci. 2018, 13, 747-764. [CrossRef]

13. Lopez, C.; Weaver, R. Placing Intentional Communities in Geography. J. Geogr. 2019, 118, 197-209. [CrossRef]

14. Feola, G. Societal transformation in response to global environmental change: A review of emerging concepts. Ambio 2014, 44 , 376-390. [CrossRef]

15. Blythe, J.; Silver, J.; Evans, L.; Armitage, D.; Bennet, N.; Moore, M.; Morrison, T.; Brown, K. The Dark Side of Transformation: Latent Risks in Contemporary Sustainability Discourse. Antipode 2018, 50, 1206-1223. [CrossRef]

16. Ballard, D.; Reason, P.; Coleman, G. Using the AQAL framework to accelerate responses to climate change. J. Integral Theor. Pract. 2010, 5, 1-18.

17. Horlings, L.; Padt, F. Leadership for Sustainable Regional Development in Rural Areas: Bridging Personal and Institutional Aspects. Sustain. Dev. 2013, 21, 413-424. [CrossRef]

18. Wilber, K. Integral Psychology: Consciousness, Spirit, Psychology, Therapy; Shambhala: Boston, MA, USA, 2000.

19. Horlings, L. The inner dimension of sustainability: Personal and cultural values. Curr. Opin. Environ. Sustain. 2015, 14, 163-169. [CrossRef]

20. O'Brien, K. Responding to climate change: The need for an integral approach. In Integral Theory in Action: Applied, Theoretical, and Critical Perspectives on the AQAL Model; Esbjørn-Hargens, S., Ed.; SUNY Press: New York, NY, USA, 2010; pp. 65-78. 
21. Horlings, L. Values in place; A value-oriented approach toward sustainable place-shaping. Reg. Stud. Reg. Sci. 2015, 2, 257-274. [CrossRef]

22. O'Brien, K. Do values subjectively define the limits to climate change adaptation? In Adapting to Climate Change: Thresholds, Values, Governance; Adger, W., Lorenzoni, I., O’Brien, K., Eds.; Cambridge University Press: Cambridge, UK, 2009 ; pp. 164-180.

23. Snow, D. Collective identity and expressive forms. In UC Irvine: Center for the Study of Democracy; University of California, Irvine: Irvine, CA, USA, 2001; Available online: https:/ / escholarship.org/uc/item/2zn1t7bj (accessed on 15 May 2020).

24. Fominaya, C.F. Collective Identity in Social Movements: Central Concepts and Debates. Soc. Compass 2010, 4, 393-404. [CrossRef]

25. Melucci, A. The Process of Collective Identity. In Social Movements and Culture; Johnston, H., Klanderman, B., Eds.; University of Minnesota Press: Minneapolis, MN, USA, 1995; pp. 41-63.

26. Brown, B.; Adger, W.N.; Devine-Wright, P.; Anderies, J.M.; Barr, S.; Bousquet, F.; Butler, C.; Evans, L.; Marshall, N.; Quinn, T. Empathy, place and identity interactions for sustainability. Glob. Environ. Chang. 2019, 56, 11-17. [CrossRef]

27. Leap, B.; Thompson, D. Social Solidarity, Collective Identity, Resilient Communities: Two Case Studies from the Rural, U.S. and Uruguay. Soc. Sci. 2018, 7, 250. [CrossRef]

28. Ergas, C. A Model of Sustainable Living: Collective Identity in an Urban Ecovillage. Organ. Environ. 2010, 23, 32-54. [CrossRef]

29. Westkog, H.; Winther, T.; Aasen, M. The Creation of an Ecovillage: Handling Identities in a Norwegian Sustainable Valley. Sustainability 2018, 10, 2074. [CrossRef]

30. Holland, D.; Fox, G.; Daro, V. Social Movements and Collective Identity: A Decentered, Dialogic View. Anthropol. Q. 2008, 81, 95-126. [CrossRef]

31. IPCC. Summary for Policymakers. In Global Warming of $1.5^{\circ} \mathrm{C}$. An. IPCC Special Report; Masson-Delmotte, V., Zhai, P., Eds.; World Meteorological Organization: Geneva, Switzerland, 2018.

32. Kates, R.W.; Travis, W.R.; Wilbanks, T.J. Transformational adaptation when incremental adaptations to climate change are insufficient. Proc. Natl. Acad. Sci. USA 2012, 109, 7156-7161. [CrossRef] [PubMed]

33. O'Brien, K.; Sygna, L. Responding to Climate Change: The Three Spheres of Transformation. In Proceedings of the Transformation in a Changing Climate, Oslo, Norway, 19-21 June 2013; pp. 16-23.

34. O'Brien, K. Is the $1.5 \mathrm{C}$ target possible? Exploring the three spheres of transformation. Curr. Opin. Environ. Sustain. 2018, 31, 153-160. [CrossRef]

35. Gillard, R.; Gouldson, A.; Paavola, J.; van Alstine, J. Transformational responses to climate change: Beyond a systems perspective of social change in mitigation and adaptation. WIRES Clim. Chang. 2016, 7, 251-265. [CrossRef]

36. Anderson, C.; Maughan, C.; Pimbert, M. Transformative agroecology learning in Europe: Building consciousness, skills and collective capacity for food sovereignty. Agric. Hum. Values 2019, 36, 531-547. [CrossRef]

37. Agyeman, J.; Bullard, R.D.; Evans, B. Exploring the Nexus: Bringing Together Sustainability, Environmental Justice and Equity. Space Polity 2002, 6, 77-90. [CrossRef]

38. Vinnari, M.; Vinnari, E. A Framework for Sustainability Transition: The Case of Plant-Based Diets. J. Agric. Environ. Ethics 2014, 27, 369-396. [CrossRef]

39. Chitewere, T. Sustainable Communities and Green Lifestyles: Consumption and Environmentalism; Routledge: London, UK, 2017.

40. Ives, C.; Freeth, R.; Fischer, J. Inside-out sustainability: The neglect of inner worlds. Ambio 2020, 49, 208-217. [CrossRef]

41. Sargisson, L. Strange Places: Estrangement, Utopianism, and Intentional Communities. Utopian Stud. 2007, 18, $393-424$.

42. Jones, L.; Tanner, T. Measuring 'Subjective Resilience': Using People's Perceptions to Quantify Household Resilience; Overseas Development Institute: London, UK, 2015.

43. Spijker, S.N.; Mathijs, E.; Parra, C. Grasping practices of self-reliance within alternative foodscapes in Flanders. Agric. Hum. Values 2020, 37, 819-832. [CrossRef]

44. Harrison, C.; Burgess, J.; Filius, P. From Environmental Awareness to Environmental Action; UCL Working Paper: London, UK, 1994.

45. Macnaghten, P.; Grove-White, P.; Jacobs, M.; Wynne, B. Public Perceptions and Sustainability in Lancashire; Lancashire County Council: Lancaster, UK, 1995.

46. Taylor, V.; Whittier, N. Collective Identity in Social Movement Communities. In Frontiers in Social Movement Theory; Morris, A.D., Mueller, C.M., Eds.; Yale University Press: New Haven, CT, USA, 1992; pp. 104-129.

47. Polletta, F.; Jasper, J.M. Collective Identity and Social Movements. Annu. Rev. Sociol. 2001, 27, 283-305. [CrossRef]

48. Anderson, J. Managing trade-offs in 'ecotopia': Becoming green at the Centre for Alternative Technology. Trans. Inst. Br. Geogr. 2011, 37, 212-225. [CrossRef]

49. Schiltz, M.M.; Vieten, C.; Miller, E.M. Worldview Transformation and the Development of Social Consciousness. J. Conscious. Stud. 2010, 17, 18-36.

50. Gamson, W. Commitment and Agency in Social Movements. Sociol. Forum 2001, 6, 27-50. [CrossRef]

51. Boyer, R. Grassroots innovation for urban sustainability: Comparing the diffusion pathways of three ecovillage projects. Environ. Plan. A 2015, 45, 320-337. [CrossRef]

52. FIC. Foundation for Intentional Communities: Communities Directory; FIC: Burnaby, BC, Canada, 2021; Available online: https: //www.ic.org/directory/ (accessed on 30 June 2021).

53. Crate, S. Climate and Culture: Anthropology in the Era of Contemporary Climate Change. Annu. Rev. Anthr. 2011, 40, 175-194. [CrossRef] 
54. Roncoli, C.; Crane, T.; Orlove, B. Fielding climate change in cultural anthropology. In Anthropology and Climate Change: From Encounters to Actions; Crate, S., Nuttall, M., Eds.; Left Coast Press: Walnut Creek, CA, USA, 2009; pp. 87-115.

55. Tsing, A. Friction: An Ethnography of Global Connection; Princeton University Press: Oxfordshire, UK, 2005.

56. Lockyer, J. Sustainability and Utopianism: An Ethnography of Cultural Critique in Contemporary Intentional Communities. Ph.D. Dissertation, University of Georgia, Athens, GA, USA, 2007.

57. Marcus, G.E.; Fischer, M. Anthropology as Cultural Critique; University of Chicago Press: Chicago, IL, USA, 1986.

58. Kanter, R.M. Commitment and Community; Harvard University Press: Cambridge, MA, USA, 1972.

59. Kuhlmann, H. The illusion of permanence: Work motivation and membership turnover at twin oaks community. Crit. Rev. Int Soc. Political Philos. 2000, 3, 157-171. [CrossRef]

60. Environment and Ecology. Federation of Egalitarian Communities. Available online: http:/ / environment-ecology.com/forumsgroups-platforms / 426-the-federation-of-egalitarian-communities-.html (accessed on 28 June 2021).

61. Twin Oaks. Welcome to Twin Oaks Community. Available online: https:/ / www.twinoaks.org/ (accessed on 13 July 2021).

62. Lushin, L. An Anarchist Path to the Liberation of Alternative Communities; Published under a Creative Commons License: Braintree, VT, USA, 2018.

63. Porta, D.D. Eventful Protest, Global Conflicts. Scand. J. Soc. Theor. 2008, 9, 27-56. [CrossRef]

64. Avelino, F.; Kunze, I. Exploring the Transition Potential of the Ecovillage Movement. In Proceedings of the European Conference on Sustainability Transitions, Amsterdam, The Netherlands, 4-5 June 2009.

65. Mansbridge, J.; Morris, A. Oppositional Consciousness: The Subjective Roots of Social Protest; University of Chicago Press: Chicago, IL, USA, 2001.

66. Riedy, C. Interior Transformation on the Pathway to a Viable Future. J. Future Stud. 2016, 20, $35-54$.

67. Lopez, C.; Weaver, R. The geographies and characteristics of intentional communities in the United States: A national-level descriptive analysis. In Proceedings of the American Association of Geographer's Annual Conference, New Orleans, LA, USA, 11 April 2018.

68. Malin, S.A.; Ryder, S.S. Developing deeply intersectional environmental justice scholarship. Environ. Sociol. 2018, 4, 1-7. [CrossRef] 